\title{
Wildlife Conservation in the Antarctic
}

By Brian Roberts

In 1964 twelve nations made conservation history when they produced the Agreed Measures for conserving the Antarctic fauna and fora, the first time such an international agreement had been achieved. The movement towards Antarctic conservation stems from the International Geophysical Year, in 1957-58, when the twelve nations, all in the Antarctic, and including the USA and the USSR, achieved an informal political truce and started collaboration in scientific research. After the end of the IGY this collaboration continued, under the aegis of the International Council of Scientific Unions and with the secretariat at the Scott Polar Research Institute, Cambridge, of which Dr. Roberts is a member. One result was the Antarctic Treaty, which came into force in 1961, and this in turn led to the Agreed Measures.

$A^{N}$ unusual combination of circumstances has made possible a A comprehensive international agreement on the conservation of wild life in the Antarctic before man has destroyed or seriously disturbed the natural ecological balance of this unique region covering more than six million square miles.

International rivalry over claims to sovereignty in the Antarctic reached a climax in the decade following the Second World War. During the International Geophysical Year, 1957-58, a number of nations made special efforts to further Antarctic scientific research, and an informal and temporary political "truce" was achieved. This, in turn, led to the negotiation of the Antarctic Treaty, which was subsequently ratified by the twelve nations primarily concerned.* At the end of the IGY the co-ordination of research programmes was continued and became the responsibility of the International Council of Scientific Unions, whose Scientific Committee for Antarctic Research (SCAR) has its secretariat at the Scott Polar Research Institute, Cambridge.

The Antarctic Treaty, which came into force on 23 June, 1961, prevented the cold war extending into the Antarctic and made provision for international co-operation in scientific investigation south of lat. $60^{\circ} \mathrm{S}$. The legal basis for sovereignty claims was "frozen" for thirty years, and the foundations laid for international consultation on all Antarctic problems. One of the items listed in the Treaty for consultation was the "Preservation and conservation of living re-

* Argentina, Australia, Belgium, Chile, France, Japan, New Zealand, Norway, South Africa, USSR, United Kingdom and the United States. The text of the Antarctic Treaty and the Recommendations of subsequent Consultative Meetings, including the "Agreed measures on the conservation of Antarctic fauna and flora" have been published by HM Stationery Office, Miscellaneous No. 23 (1965), Cmnd. 2822, (3s.). 
sources". This was included for two reasons: first, there was abundant evidence that biologists in all the nations concerned were strongly advocating effective conservation measures in the Antarctic before it would be too late, and, second, this was known to be a relatively uncontroversial subject on which all the nations concerned might expect to agree. Many other problems seemed much less promising for amicable discussion and joint action during the early stages of this experiment in international co-operation.

For these reasons, one of the most difficult political problems usually associated with international action on conservation did not arise. The periodical Consultative Meetings initiated by the Antarctic Treaty provided a ready-made forum for discussions on conservation. The subject was actively pursued at the Consultative Meetings held in Canberra (1961), Buenos Aires (1962), and Brussels (1964). The Brussels meeting produced the "Agreed measures for the conservation of Antarctic fauna and flora", which are summarised at the end of this paper, and also three additional 'Recommendations' to the participating governments: the first requires interim action by each nation during the period before the measures come into force; the second recognises the initiative of SCAR and invites the organisation "to prepare reports from time to time on this subject, and especially at this time on the matters that it considers should be listed in the Annexes to the Agreed measures"; the third relates to pelagic sealing and the taking of fauna on pack ice, a subject which raises some intractable problems about the legal status of floating ice on the High Seas. These problems of the High Seas needed more study and were therefore left over for consideration at the next Antarctic Treaty Consultative Meeting to be held at Santiago in November, 1966.

\section{The Political Realities}

At this stage it is useful to stimulate further discussion among biologists, bearing in mind that the agreed channel for advice to governments is through SCAR, and hence through the national organisations associated with SCAR. In the United Kingdom this is the Royal Society. Almost every practical proposal bristles with political and/or legal difficulties, but this should certainly not deter conservationists and biologists from offering independent advice on what they consider to be the basic facts and requirements.

Biological advice will be most effective if it can be organised to conform with some of the political realities. The following comments are relevant:

(1) Whales have been deliberately excluded from this particular approach to conservation. The nations concerned with Antarctic whaling are not all signatories of the Antarctic Treaty, while the established forum for discussion of whaling problems is the International Whaling Commission. There is no logic in confusing or postponing other conservation measures because one of them is especially difficult.

(2) Recommendations about the Treaty Area (south of lat. $60^{\circ} \mathrm{S}$.) should be separated from those for the sub-Antanctic islands lying further 
north. The former can be tackled through the machinery of the Antarctic Treaty, while the latter must be dealt with by the individual governments which exercise undisputed sovereignty. It will not help the basic biological objectives if proposals for conservation measures for these two regions are confused together. Biologists who are interested in the sub-Antarctic islands north of $60^{\circ} \mathrm{S}$. should direct their opinions to the appropriate recognised administrative authorities. These may be summarised as at present understood by the United Kingdom Government, from west to east: Tierra del Fuego (Argentina and Chile), Falkland Islands,* South Georgia,* South Sandwich Islands," Tristan da Cunha and Gough Island (United Kingdom), Prince Edward Islands (South Africa), Iles Crozet, Archipel de Kerguelen, Ile Saint Paul and Ile Amsterdam (France), Heard Island and Macquarie Island (Australia), and the sub-Antarctic islands of New Zealand. It appears that only the regions marked with an asterisk are still under disputed sovereignty.

(3) In the Treaty Area there remains a very large field for advice and action. There are three special fields for advice, either through SCAR, or direct to the responsible government departments: the designation of Specially Protected Species (Article VI and Annex A); the designation of Specially Protected Areas (Article VIII and Annex B); and further study of problems connected with the prevention of aocidental introduction of parasites and diseases (Article IX and Annexes C and D).

Specially Protected Species. The list in Annex A should be a simple list of named species. For obvious reasons, this list must be very shont, easy to remember, and the species must be capable of identification by nearly all visitors. In most cases it will be more effective to give special protection to selected areas where these species are known to breed, and from which they can spread. Individual plants and minute invertebrates cannot be effectively protected by name because of the difficulty of identification and often this can only be achieved by protecting the natural balance of the whole ecelogical system in which they live. The Agreed Measures already afford a satisfactory measure of protection for all Antaretic species. This schedule should therefore be limited to species for which there are special arguments.

Specially Protected Areas. The list in Annex B must reflect the need to preserve habitats. We want to preserve a limited number of total interrelationships or patterns of life. This can only be done by preserving carefully selected samples of the habitat As mentioned above, many of the most interesting small forms of life can only be protected in this way. The areas need not be large and not many of them are initially necessary. If we protect species for scientific purposes, it is obvious that scientists must be allowed to study them. The object of the Specially Protected Areas is that only qualified research workers who know what they are doing should ordinarily enter these areas at times when the species are most vulnerable. At other seasons, when breeding birds or mammals are absent and moss and lichen banks are snow-covered, there is no need to forbid the entry or men on foot, although there is reason to exclude heavy vehicles which could cause permanent damage. These scheduled areas must be precisely defined, with explanations which will allow periodical revision as knowledge advances.

Accidental introduction of parasites and diseases. It must be obvious that the precautions listed in Annexes $C$ and $D$ can be improved. We still understand very little of this whole problem, which may well be of greater importance for conservation in the Antarctic than the more familiar depredations of man. Here is a field in which research should receive all possible encouragement.

Ten of the twelve Antarctic Treaty governments have already 
notified approval of the Brussels Recommendations, but seven have temporarily excepted Recommendation VIII, which refers to the Agreed Measures on Conservation. This exception is due to the necessity for legislation or other administrative action before the Agreed Measures can be formally approved. The constitutional procedures in each country are different and will take some time. Meanwhile, it is satisfactory to record that nearly all the governments concerned have already taken interim action to ensure adequate conservation measures, so far as this can be done without legislation.

\section{SUMMARY OF THE AGREED MEASURES FOR. THE CONSERVATION OF ANTARCTIC FAUNA AND FLORA}

The full text, which can be obtained from HMSO (3s.), consists of a Preamble, fourteen Articles and four Annexes.

The preamble sets out a few basic principles and purposes. Articles I to $\mathrm{V}$ cover the area of application (south of $60^{\circ} \mathrm{S}$., but with reservations necessitated by the law of the High Seas), definitions, procedure, etc. Articles VI-IX, which contain the main substance of the agreement, are reproduced in full below:

\section{Article VI-Protection of native fauna}

1. Each Participating Government shall prohibit within the Treaty Area the killing, wounding, capturing or molesting of any native mammal or native bird, or any attempt at any such act, except in accordance with a permit. 2. Such permits shall be drawn in terms as specific as possible and issued only for the following purposes:

(a) to provide indispensable food for men or dogs in the Treaty Area in limited quantities, and in conformity with the purposes and principles of these Agreed Measures;

(b) to provide specimens for scientific study or scentific information;

(c) to provide specimens for museums, zoological gardens, or other educational or cultural institutions or uses.

3. Permits for Specially Protected Areas shall be issued only in accordance with the provisions of Article VIII.

4. Participating Governments shall limit the issue of such permits so as to ensure as far as possible that:

(a) no more native mammals or birds are killed or taken in any year than can normally be replaced by natural reproduction in the following breeding season;

(b) the variety of species and the balance of the natural ecological systems existing within the Treaty Area are maintained.

5. The species of native mammals and birds listed in Annex $A$ of these Measures shall be designated "Specially Protected Species", and shall be accorded special protection by Participating Governments.

6. A Participating Government shall not authorise an appropriate authority to issue a permit with respect to a Specially Protected Species except in accordance with paragraph 7 of this Article.

7. A permit may be issued under this Article with respect to a Specially Protected Species, provided that:

(a) it is issued for a compelling scientific purpose, and

(b) the actions permitted thereunder will not jeopardise the existing natural ecological system or the survival of that species. 


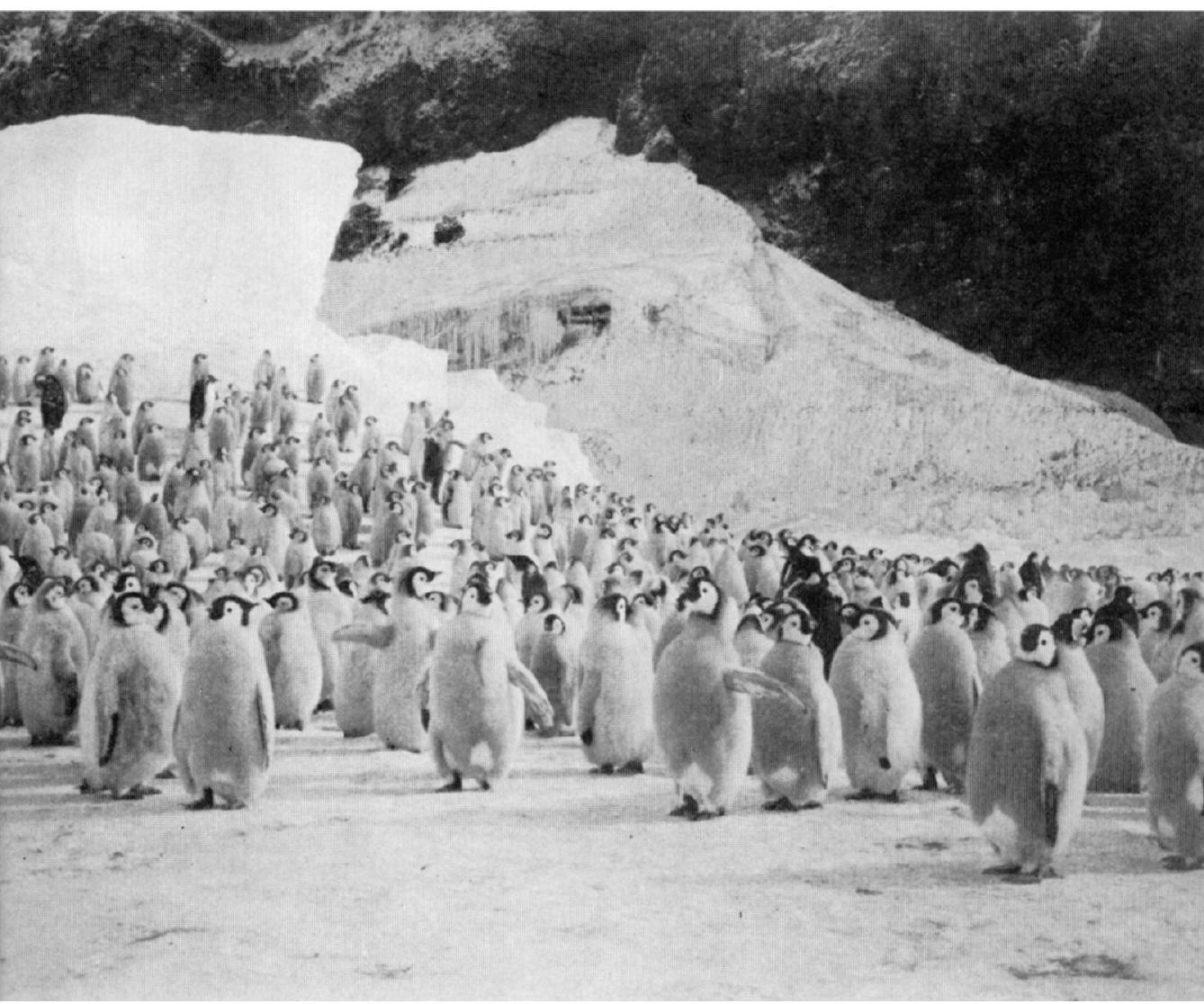

\section{EMPEROR PENGUINS}

Plate 5: Young emperor penguins at Cape Crozier, Antarctica. 
Plate 6:

ELEPHANT SEAL.

This seal breeds mainly in the sub-Antarctic islands, also on the fast ice in the South Orkney Islands and in isolated places on the Antarctic mainland. Its numbers are increasing. Ministere de la France d'Outre Mer

Plate 7 and 8 below:

Left: CRABEATER SEAL, the commonest species but now in danger of exploitation for skins.

Colin Bertram

Right: SOUTHERN FUR SEAL at Cough Island, now increasing after being fwice decimated in the last century.

Gough Island Scientific Survey 
WILDLIFE OF THE ANTARCTIC

CHINSTRAP PENGUINS characteristic of Lower Antarctica. Colin Bertram

Plates 10 and 11 below: Left: GENTOO PENGUIN common in the Antarctic peninsula and the sub-Antarctic islands. Brian Roberts

Right: ADELIE PENCUINS, the commonest Antarctic species. G. Murray Levick
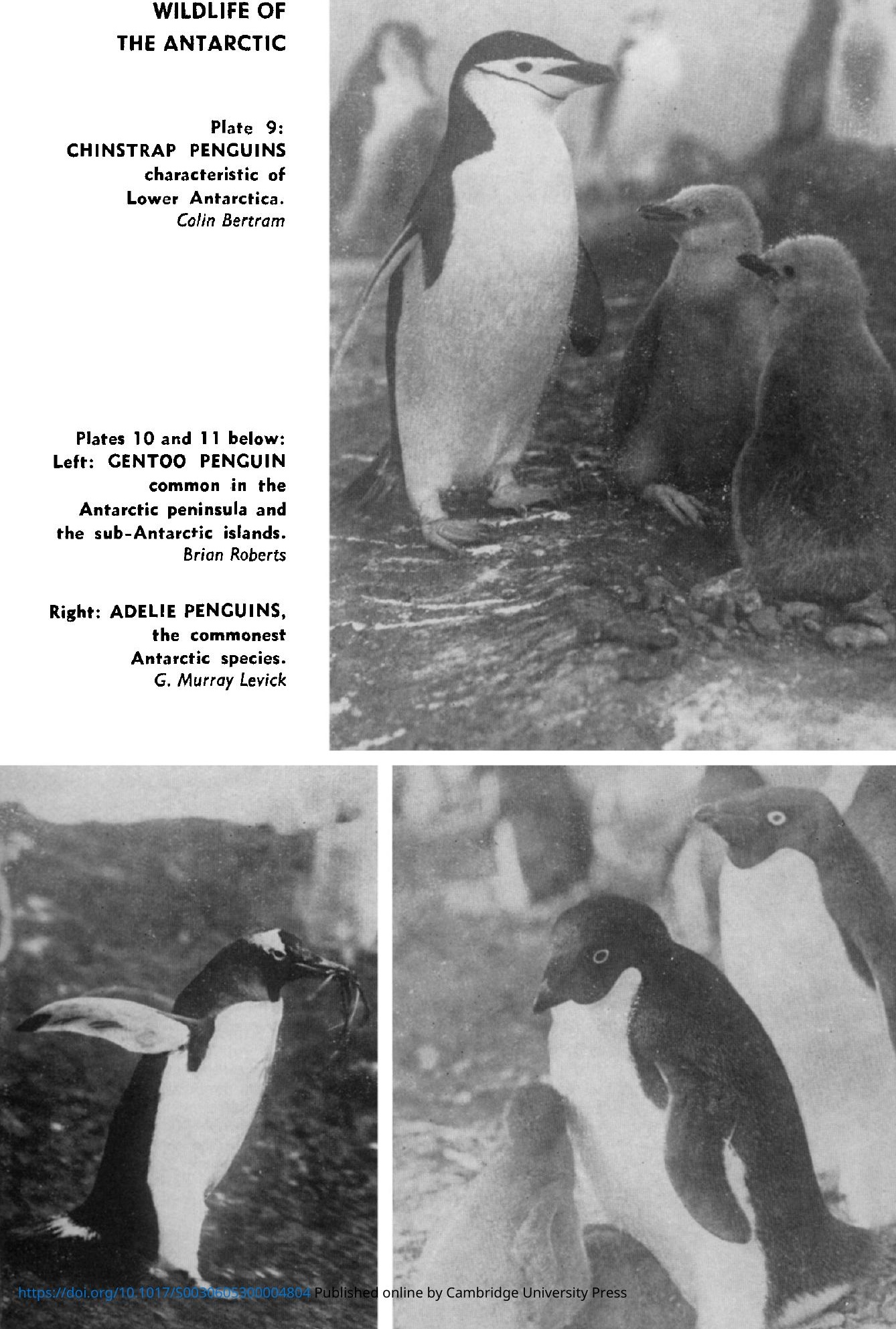


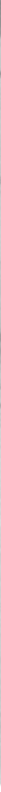

Brion Roberts

KING PENGUINS

Plate 12: A créche of young birds about nine months old. King penguins are largely a sub-Antarctic species, but they spread southwards into the Antarctic Treaty Area. 


\section{Article VII-Harmful interference}

1. Each Participating Government shall take appropriate measures to minimise harmful interference within the Treaty Area with the normal living conditions of any native mammal or bird, or any attempt at such harmful interference, except as permitted under Article VI.

2. The following acts and activities shall be considered as harmful interference:

(a) allowing dogs to run free;

(b) flying helicopters or other aircraft in a manner which would unnecessarily disturb bird and seal concentrations, or landing close to such concentrations (e.g. within $200 \mathrm{~m}$ ),

(c) driving vehicles unnecessarily close to concentrations of birds and seals (e.g. within $200 \mathrm{~m}$ ),

(d) use of explosives close to concentrations of birds and seals,

(e) discharge of firearms close to bird and seal concentrations (e.g. within $300 \mathrm{~m}$ ),

(f) any disturbance of bird and seal colonies during the breeding period by persistent attention from persons on foot.

However, the above activities, with the exception of those mentioned in (a) and (e) may be permitted to the minimum extent necessary for the establishment, supply and operation of stations.

3. Each Participating Government shall take all reasonable steps towards the alleviation of pollution of the waters adjacent to the coast and ice shelves.

\section{Article VIII-Specially protected areas}

1. The areas of outstanding scientific interest listed in Annex B shall be designated "Specially Protected Areas" and shall be accorded special proteotion by the Participating Governments in order to preserve their unique natural ecological system.

2 . In addition to the prohibitions and measures of protection dealt with in other Articles of these Agreed Measures, the Participating Governments shall in Specially Protected Areas further prohibit:

(a) the collection of any native plant, except in accordance with a permit;

(b) the driving of any vehicle.

3. A permit issued under Article VI shall not have effect within a Specially Protected Area except in accordance with paragraph 4 of the present Article. 4. A permit shall have effect within a Specially Protected Area provided that:

(a) it was issued for a compelling scientific purpose which cannot be served elsewhere; and

(b) the actions permitted thereunder will not jeopardise the natural ecological system existing in that Area.

\section{Article IX-Introduction of non-indigenous species, parasites and diseases}

1. Each Participating Government shall prohibit the bringing into the Treaty Area of any species of animal or plant not indigenous to that Area, except in accordance with a permit.

2. Permits under paragraph 1 of this Article shall be drawn in terms as specific as possible and shall be issued to allow the importation only of the animals and plants listed in Annex $C$. When any such animal or plant might cause harmful interference with the natural system if left unsupervised within the Treaty Area, such permits shall require that it be kept under controlled conditions and, after it has served its purpose, it shall be removed from the Treaty Area or destroyed. 
3. Nothing in paragraphs 1 and 2 of this Article shall apply to the importation of food into the Treaty Area so long as animals and plants used for this purpose are kept under controlled conditions.

4. Each Participating Government undertakes to ensure that all reasonable precautions shall be taken to prevent the accidental introduction of parasites and diseases into the Treaty Area. In particular, the precautions listed in Annex D shall be taken.

The remaining Articles provide inter alia, for the collection and international exchange of records (including records of permits), and there are some formal provisions about approval, amendment, etc.

Annexes A and B, the lists of "Specially Protected Species" and "Specially Protected Areas", are still blank and await discussion at the next Consultative Meeting. Annexes $C$ and $D$ are reproduced in full below:

\section{Annex C-Importation of animals and plants}

The following animals and plants may be imported into the Treaty Area in accordance with permits issued under Article IX (2) of these Agreed Measures:

(a) sledge dogs.

(b) domestic animals and plants,

(c) laboratory animals and plants.

\section{Annex D-Precautions to prevent accidental introduction of parasites and diseases into the Treaty Area}

The following precautions shall be taken:

1. Dogs: All dogs imported into the Treaty Area shall be inoculated against the following diseases:

(a) distemper;

(b) contagious canine hepatitis;

(c) rabies;

(d) leptospirosis ( $L$. canicola and $L$, icterohaemorrhagicae).

Each dog shall be inoculated at least two months before the time of its arrival in the Treaty Area.

2. Poultry: Notwithstanding the provisions of Article IX (3) of these Agreed Measures, no living poultry shall be brought into the Treaty Area afiter 1st July, 1966.

\section{The Wildlife to be Conserved}

Six species of seal occur in the area: crabeater, Weddell, leopard, Ross, elephant and fur seals. The Ross seal is much the rarest, with an estimated world population of about 50,000. The crabeaters are the commonest, but also the most vulnerable. Last year a reconnaissance for commencial exploitation of the crabeaters discovered a new breeding ground on the open pack ice, far from land. The southern fur seals and the elephant seals, which breed on shore, and were twice nearly wiped out by man during the 19th century, are at last beginning to recover their former numbers.

Antarctic birds are remarkable in several ways. The list is strikingly short: in the whole region south of the Antarctic Convergence only about 80 species have been recorded, and less than half are known to breed. Only five are true land birds: a pipit, two closely related species 
of sheathbill and two ducks. More than half the breeding species are petrels, the most characteristic birds of the south polar region. Only 14 bird species breed on the continent itself: emperor, adelie, gentoo and chinstrap penguins, silver-grey fulmar, Cape pigeon, prion, snow petrel, Antarctic and Wilson's petrels, blue-eyed shag, Dominican gull, Antarctic tern and skua.

There is life on the exposed inland mountains and nunataks, although it is very scanty. Roughly speaking, if you put a competent zoologist, with the proper equipment, down on any large exposed rock area in Antarctica he is likely to find life, though many of the ice-free areas are too cold, too dry or too windy to support life. Distributions noted so far almost certainly represent places where skilled collecting has been done rather than the true distribution of any particular species. So far fewer than 100 land arthropods have been discovered. Collembola and mites are probably the southernmost permanent terrestrial animal inhabitants, although rotifers may exceed them slightly. All Antarctic mammals, birds, invertebrates, and plants have evolved special adaptations to enable them to flourish in an extremely rigorous environment, and the detailed studies, now only just beginning, will certainly be highly rewarding.

\section{Man Could Bring Disaster}

Most of the Antarctic fauna exists on what is believed to be a marginal basis of stability, and human influences could easily tip the scale in critical cases. We have discarded the old argument that a species is in no danger because it is still common. The seals, petrels and penguins are especially vulnerable because they concentrate for breeding, sometimes in vast numbers, on relatively few small island sites where introduced predators or diseases can have catastrophic results. The scarcity of breeding sites in relation to huge areas of marine feeding grounds presents a special challenge for conservationists. The sudden increase in human activities in places where the fauna has been isolated from outside infection and there is no rapid bacteriological decomposition brings a potential demographic crisis. The Antarctic ecosystems can probably be destroyed even more rapidly than those of temperate regions. Much further research is essential to identify the real dangers and to provide the necessary basis for concerted remedial action.

Meanwhile let us do our best to preserve for our successors some of the most interesting and exciting biological spectacles to be found anywhere on earth: the great seal and penguin colonies; the soaring of the wandering albatross; the fantastic evening flight of uncountable millions of prions returning to their nesting islands, when the whole surface of the sea appears to be moving against the wind in a solid sheet of gliding petrels as far as the eye can see; a sperm whale leaping clear of the water; a small pink Colobanthus flowering in isolated desolation-those who have been fortunate enough to witness these things will never forget the joy they evoked. 